\title{
Aportaciones metodológicas y económicas al sistema presidial de Texas, 1720-1772
}

\author{
Dr. José Manuel Serrano Álvarez* \\ Dr. Allan J. Kuethe**
}

\begin{abstract}
Resumen:
Este trabajo pretende mostrar, por un lado, aspectos metodológicos nuevos de los estudios de la financiación militar en Indias, y en concreto los referentes a la frontera del septentrión novohispano; por otro lado busca responder a cuestiones vitales de la fiscalidad militar de la provincia de Texas en el siglo XVIII. Las reformas emprendidas por Rivera en 1729 y Rubí en 1772 constituyen el centro de esta investigación y responde al interés por conocer el gasto total de la provincia, la problemática de los canales de financiación y el grado de aplicación de ambos reglamentos, en especial el de Rivera, tan criticado por la historiografía. Las aportaciones que aquí se recogen están basadas en fuentes primarias de archivo, nunca usadas hasta ahora para tratar la fiscalidad militar de la frontera norte, y sus conclusiones muestran el grado de implicación de las autoridades militares virreinales en la expansión del septentrión en la provincia de Texas, así como las incidencias de los situados sobre la población civil y militar.
\end{abstract}

Palabras Clave: Texas, Nueva España, Sistema Presidial.

La historia de la Texas colonial en el siglo XVIII ha gozado de un considerable aprecio por parte de muchos investigadores. El hecho de haber sido tierra de frontera, dura e inexpugnable a veces, atrajo la atención no sólo de los españoles del siglo XVIII, al fin y al cabo muy interesados en mantener a raya a los franceses de la Luisiana, sino también contemporáneamente a muchos historiadores deseosos de conocer los mecanismos que hicieron de esta provincia del norte del Virreinato de Nueva España una de las que más recursos de toda índole absorbió.

El problema historiográfico ha surgido desde el momento en que existen contradicciones a la hora de analizar las causas, y sobre todo las consecuencias, de diversas disposiciones legales que afectaron grandemente la estructura interna de la provincia. En especial nos referimos aquí al reglamento, acompañado de muy interesantes comentarios sobre Texas, de Pedro de Rivera, del año 1729, así como al del marqués de Rubí que en 1772 reemplazó al anterior después de no poca polémica. Desde entonces, los historiadores no se han puesto de acuerdo en muchos de los aspectos esenciales de dichos reglamentos, especialmente en lo referente a los recortes 
presupuestarios, desplazamiento, eliminación o creación de presidios, y en las diferentes relaciones políticas entre los gobernantes de Texas y las autoridades de Nueva España. En nuestra opinión, el nivel de conocimientos alcanzado, muy especialmente por los historiadores norteamericanos, acerca de las misiones, disposición de los presidios, comunidades indias y lo que podríamos llamar historia política de Texas durante el siglo XVIII, se puede considerar de excelente. ${ }^{1}$

\section{Estado de la cuestión y planteamiento metodológico}

Un aspecto que nos ha preocupado grandemente es la constatación de que, por parte de la historiografía actual, la mayoría de los estudios son excesivamente regionalistas, compartimentados y aislados, sin solución de continuidad, y lo que es más importante, sin una perspectiva global, incluso imperial. Este problema ya ha sido detectado con anterioridad, y es especialmente grave en el caso de una parte de la historiografía norteamericana. ${ }^{2}$ Estamos de acuerdo con David J. Weber ${ }^{3}$ en que es imprescindible, para paliar la anterior deficiencia, unificar trabajos y abordar el estudio de la frontera norte con una perspectiva global, incluso cuando se hacen únicamente estudios de una parte de esa amplia línea fronteriza. En este sentido, es constatable que algo se ha avanzado en esa dirección, no sólo con la valiosa obra de Weber, sino también con otras dos anteriores que resultan de gran utilidad. John Francis Bannon con su Spanish Borderlands Frontier, 1513-1821, y especialmente, en cuanto a una óptica más española y con un amplio aparato crítico de documentos de archivo, la excelente Don José de Gálvez y la Comandancia General de las Provincias Internas del Norte de Nueva España, del profesor Luis Navarro García, obra que, aunque editada en 1964, constituye un referente ineludible y un ejemplo de estudio de conjunto de los pormenores de la frontera norte partiendo del análisis detallado de un componente, en este caso, la visita y posterior implantación de la política fronteriza de José de Gálvez.

El conocimiento que actualmente se tiene de la provincia de Texas durante el período colonial es muy amplio, y tal vez podría ser calificado de excelente. Prácticamente todos los aspectos más significativos han sido y están siendo abordados por eminentes historiadores, especialmente norteamericanos. El nivel de comprensión que tenemos acerca de las misiones texanas o de la política referente a los indios locales es muy elevado. ${ }^{4}$ Sin embargo un aspecto de vital importancia ha escapado 
permanentemente al estudio en profundidad por parte de los historiadores de la frontera, como es el de la fiscalización de la política militar de la zona, o dicho de otra forma, el control, organización y administración del aparato militar español que controlaba la provincia de Texas como parte integrante del cordón presidial novohispano. Aunque ha habido acercamientos parciales, la realidad militar en Texas durante el siglo XVIII se ha visto esencialmente desde el prisma de la capital del virreinato, y en general la frontera de Texas no ha sido considerada un lugar prominente desde el punto de vista militar. Su administración militar no ha sido estudiada, y lo que tenemos, en esencia, son estudios parciales sobre los presidios y sus principales personajes: una visión sin duda interesante pero, una vez más, compartimentada y aislada de la política general de defensa de la frontera.

¿Qué sabemos realmente de los mecanismos que gobernaban la economía presidial en Texas y en el resto de enclaves fronterizos? ¿Cómo eran mantenidos? ¿Qué fiscalización ejercían los oficiales reales de México, o el propio virrey, sobre el gasto militar de Texas? ¿Cómo llegaba el dinero allí y en qué forma? Estas y otras cuestiones similares no han sido, hasta ahora, estudiadas, y menos aún usando con profusión material de archivo. Realmente desconocemos mucho de la economía militar de la frontera, porque parecía que lo importante en sí era el presidio y las misiones circundantes. Sin embargo, se ha pasado por alto que sin el dinero del virreinato no se habrían sostenido los presidios fronterizos, y que éste necesitaba algún tipo de control. ¿Quiénes fiscalizaban el dinero y, principalmente cuánto se envió?

No se ha realizado, hasta el momento, un estudio exhaustivo del gasto militar que generaron las guarniciones texanas, ni de los canales por donde discurría la plata que debía soportar el costoso sistema presidial del norte del virreinato. En nuestra opinión, el problema fundamental de los presidios de Texas en el siglo XVIII estribaba fundamentalmente en la correcta adecuación de los medios económicos locales con los netamente monetarios que desde México les llegaban para su sustento. Dicho de otra forma, aunque bien es sabido que la mayoría de las misiones y presidios no estaban situados en tierras que generaran una riqueza local importante, vía bienes agropecuarios, el situado ${ }^{5}$ enviado desde México resultaba vital para mantener compactadas las guarniciones y que sus miembros tuviesen capacidad de compra de aquellos productos que, sencillamente, ellos no podían producir. La red de intercambios que esto provocaba con otras áreas, incluso con los franceses al este de Texas, es la clave para comprender 
el difícil equilibrio en que se mantuvieron las guarniciones de la provincia durante la práctica totalidad del siglo XVIII. Por consiguiente, los aspectos económicos y financieros de la provincia de Texas suponen un elemento fundamental para entender los cambios producidos a raíz de la visita de Rivera, así como para comprender la utilidad o no de su política de recortes presupuestarios.

Esta investigación pretende resolver estas cuestiones como parte integrante de una política imperial de defensa, y como una forma de comprensión de la realidad de Texas en el organigrama de defensa de la frontera norte. Introducimos elementos de análisis nuevos y una metodología completamente diferente de la que hasta ahora se ha venido utilizando, esencialmente, porque este estudio parte de las cajas reales y de la información que trasmite, hasta ahora muy poco utilizada y peor valorada.

La información que recogen las cajas reales es excepcionalmente rica, variada y mucho más rigurosa de lo que muchos autores piensan. Hasta el presente, no ha habido un esfuerzo sostenido por historiadores o grupos de investigación que traten de dilucidar problemas historiográficos partiendo del estudio riguroso de la contabilidad virreinal. A las conocidas obras de Tepaske y Klein, ${ }^{6}$ o a las menos difundidas de Alvaro Jara ${ }^{7}$ o Engel Sluiter ${ }^{8}$ ha seguido un relativo y notable vacío en los últimos años, especialmente en cuanto al aspecto metodológico. Las mencionadas obras de Tepaske y Klein, ampliamente difundidas y que son citadas y usadas de manera continuada por la inmensa mayoría de historiadores, han supuesto, en cierta medida, un retroceso en cuanto a la aceptación de las cajas reales como fuentes de información, especialmente porque se tratan exclusivamente de trascripciones de los sumarios de cargo y data, transcripciones que en algunos casos tienen notables deficiencias y errores, pero que esencialmente no contienen depuraciones de sus cifras. Esto ha llevado a disminuir el valor historiográfico de estas series por cuanto no sabemos con certeza dónde se encuentran los principales errores, pese a que el propio Klein ha advertido en algunos artículos posteriores, y en la introducción de su libro Las finanzas americanas del imperio español, 1680-1809, que "posiblemente" sus datos no son del todo exactos. Sin embargo, no se ha llevado la tan deseada depuración de esas cuentas, tan necesarias para la historiografía.

Así las cosas, es comprensible que en el estudio de los componentes fiscales y económicos de la política imperial de defensa, y en general de la política económica de los Borbones, se hayan cometidos errores graves al no poseer series estadísticas para 
analizar en profundidad y con rigor los diferentes estadios de la acción del gobierno virreinal novohispano, no sólo en la frontera norte, sino también en el llamado Gran Caribe. De esta manera, eminentes historiadores como Carlos Marichal, en su difundida obra La bancarrota del virreinato. Nueva España y las finanzas del Imperio español, 1780-1810, llega a afirmar que "las remesas mexicanas representaron el 75\% del total de los ingresos registrados por la tesorería principal de Cuba entre 1765 y 1788: durante este período habrían llegado a La Habana 57.739.000 pesos". 9 Estas cifras son absolutamente insostenibles, como en su momento estaremos en posición de demostrar, ${ }^{10}$ pero lo más importante es que las fuentes de las que se extraen estas cifras son siempre de dudoso valor, aunque repetidas una y otra vez por no pocos historiadores: Alejandro von Humboldt, Ramón de la Sagra y las series de Tepaske y Klein constituyen su fuente principal. Aunque el valor de la labor de Humboldt no la vamos a discutir aquí, especialmente sus excelentes informes sobre lo que vio y entendió de las diferentes partes del imperio español que visitó, sí son altamente cuestionables sus citadas tablas estadísticas. Lo mismo se pueden decir de las de Ramón de la Sagra, publicadas por primera vez en 1831 y que carecen de rigor metodológico y de fuentes precisas.

Precisamente por ello, la labor de no pocos análisis sobre la administración militar se puede ver cuestionada por la falta de una base sólida de datos fiscales y económicos, y especialmente por la carencia de reglas metodológicas discernibles y clarificadoras de la realidad económica local. Para paliar estas deficiencias, en los últimos años hemos llevado una importante labor de concreción de pautas de comportamiento metodológicas que sean la base de nuestras posteriores investigaciones. ${ }^{11} \mathrm{El}$ éxito de lo hasta ahora realizado supone una clara aceptación de que, sin unas reglas claras de depuración de la contabilidad virreinal, la sombra de la duda estará siempre presente sobre cualquier trabajo de esta naturaleza.

Aunque en esencia estamos de acuerdo con las tesis de Marichal acerca de la importancia del situado en el engranaje imperial caribeño, así como en el peso de las transferencias americanas de plata a la península, no podemos aceptar completamente sus datos al estar basados en fuentes aún no sometidas a crítica documental y metodológica. Toda la argumentación de una buena parte de la historiografía mexicana se sostiene basándose en las ya aludidas series fiscales, así como en otras aún más dudosas, como la de Canga Argüelles. ${ }^{12}$ Por otra parte, la excelente obra de José 
Patricio Merino sobre las cuentas generales del Estado ${ }^{13}$ supone un enorme esfuerzo metodológico en el sentido deseado, pero deben ser revisadas las cifras provenientes de la Depositaría de Indias, claves para entender las transferencias a la península en la época clave de cambios económicos de Múzquiz, Gálvez o Floridablanca, ya que hemos detectado desviaciones importantes que suponen cambios significativos que varían sustancialmente algunas interpretaciones actuales.

Por consiguiente, se han aplicado en este trabajo reglas metodológicas de análisis crítico de la documentación contable de manera que se eviten los errores de contabilidad, repeticiones, duplicidades y errores internos de caja, algo que es especialmente vital ya que la mayoría de los datos que se analizarán aquí proceden de la caja central de México, sin duda, la más importante, y por ello, la que más dificultades pone al investigador. No se ha hecho, por tanto, una mera trascripción de los datos reflejados en los diversos ramos, sino que se ha estudiado detenidamente cada ramo y cada rublo, no sólo con la idea de evitar errores, sino especialmente para extraer importante información histórica, económica y jurídica de la contabilidad virreinal. Porque una de las grandes virtudes que tiene el trabajo depurador de la contabilidad virreinal es precisamente que ofrece al historiador una gran masa de información anexa a la meramente contable, que puede ser de inestimable ayuda para explicar diferentes comportamientos. En este sentido, demostraremos cómo con este tipo de análisis es posible no sólo conocer las cantidades de situados que pudieron discurrir por y hacia Texas, sino también en qué medida y bajo qué naturaleza.

El estudio exhaustivo del gasto militar tiene también la ventaja de darnos claves significativas acerca de quiénes eran los que realmente controlaban el dinero en la línea de frontera, cómo se redistribuía, cómo y de qué manera llegaba en última instancia a los soldados y personal civil que vivía con ellos, y si verdaderamente estuvo correctamente diseñado el entramado que distribuía primero, y canalizaba después, la plata mexicana por la peligrosa frontera norte del virreinato.

Lejos de juzgar desde el punto de vista político las actuaciones de Rivera, y las posteriores de Rubí, este trabajo pretende aportar elementos nuevos para el debate, tales como los gastos militares de cada uno de los presidios y la estructura de los canales de financiación que, como un hilo umbilical, unían México con Texas. Partiendo de estos datos, inéditos hasta ahora, nos será mucho más fácil comprender el verdadero grado de 
aplicación de las reformas de Rivera, y si éstas fueron, efectivamente, y como se han argüido, unos "recortes draconianos" o bien "apenas afectaron a realidad existente". 14

\section{Texas en la etapa de Rivera y el problema de la circulación monetaria}

Al comenzar el siglo XVIII las provincias internas tenían sólo quince presidios, que se extendían desde Sonora hasta Nueva Vizcaya, de los cuales ninguno estaba en Texas, tierra aún no ocupada formalmente pese a los varios fallidos intentos del siglo XVII. ${ }^{15}$ El costo para las arcas mexicanas de los 562 hombres que componían estas guarniciones era de 251.883 pesos anuales. ${ }^{16}$ Esto suponía una media por hombre de algo más de 448 pesos, una cifra realmente alta si se la compara con otras guarniciones de áreas de importancia militar, como era el caso de Cartagena de Indias, que en el mismo período tenía una guarnición de 520 hombres y un costo anual de 97.136 pesos, es decir 186 pesos por hombre y año de media. ${ }^{17}$ Es cierto que la tierra de frontera, ruda y violenta, era mucho más cara, y que existía la necesidad imperiosa de conseguir productos que habitualmente había que comprar fuera del recinto presidial. Sin embargo, las diferencias en cuanto al costo eran tan significativas que cabe preguntarse, como ya lo hicieran los contemporáneos, si la utilidad del sistema estaba directamente relacionado con su costo. No hay que olvidar que por el costo anual de las guarniciones del norte de Nueva España era posible construir en el astillero de La Habana cuatro navíos de 60 cañones sin ninguna dificultad. ${ }^{18}$ Otro elemento a tener en cuenta es que estas guarniciones eran sufragadas por cajas reales muy cerca, o relativamente, de los destinos de los situados, no estando ninguna sostenida directamente desde la capital del virreinato. Así, las cajas emisoras eran Zacatecas, Guadiana y Guadalajara, situación que se rompería precisamente en la década de 1720, cuando México tomó el mando del envío directo de los situados de todos los presidios fronterizos, incluyendo los primeros de Texas. ${ }^{19} \mathrm{Y}$ de igual forma, el situado, pese a que era enviado fundamentalmente en dinero, acababa en manos de los soldados convertidos directamente en artículos y bienes de consumo, a precios desorbitantes, debido al control que sobre el tránsito del dinero ejercían ciertos capitanes haciendo las veces de situadistas-comerciantes. La consecuencia era un sistema extremadamente caro, en donde era raro que un presidio estuviera al completo, y además donde la corrupción entre los mismos gobernantes militares estaba a la orden del día. ${ }^{20}$ 
Y ésta fue, precisamente la situación que se encontró Pedro de Rivera cuando a principios de la década de 1720 se le encomendó la tarea de, primero, realizar una amplia inspección de todos los presidios $\mathrm{y}$, segundo, conformar un reglamento, fundamentalmente de índole económico, que sirviera de acicate para una frontera que, más que en expansión, estaba en peligro de franca regresión debido al empuje francés desde el este. ${ }^{21}$

Una vez rota la barrera psicológica que suponía la frontera de río Grande con la creación del presidio de San Juan Bautista, en 1701, la frontera se fue adentrando hacia el este, en dirección a Texas, donde ya definitivamente se crearon cuatro presidios permanentes: Ntra Sra de los Dolores (1716), San Antonio de Bejar (1718), Ntra Sra del Pilar de las Adais (1721) - que hacía de capital de la provincia, y Ntra. Sra. de Loreto de la Bahía de Espíritu Santo (1722). El problema de estos primeros presidios fue que su establecimiento vino dado por circunstancias exógenas, como eran los establecimientos franceses en torno al río Rojo (Natchitoches). La reacción española fue la expedición del marqués de Aguayo, en 1720 y 1721, y la fundación del presidio de los Adais, justo en el límite oriental de la provincia de Texas, y la refundación del presidio de los Dolores, llamado habitualmente Presidio de los Tejas. ${ }^{22}$ Estos presidios texanos, sin embargo, no eran más que uno de los elementos del sistema presidial que partiendo de California llegaba hasta el este de Texas, por lo demás, tremendamente costoso. Justo antes de la visita de Rivera, el conjunto de presidios, en total veintidós, costaba a la corona 444.883 pesos anuales, de los que buena parte se los llevaba Texas. ${ }^{23}$ Sin embargo, los soldados no tenían un sueldo homogéneo, sino que dependía en buena medida del presidio que le tocara. Por lo demás, el dinero, que desde 1726 se canalizó hacia Texas directamente desde la capital del virreinato, generaba no pocas polémicas entre los capitanes de presidio, los soldados e incluso entre los franciscanos, elementos muy activos que jugaron un papel decisivo en la historia económica y social de la Texas colonial.

Otra cosa bien distinta era el control sobre los gastos presidiales. No era nuevo el enorme costo que ocasionaba el transporte de hombres o mercancías desde Nueva España a Texas, por una ruta que desde el Saltillo llegaría finalmente a los Adais. La falta de control tanto de las mercancías como del dinero transportado era bien conocida. Por eso, el objetivo fundamental de Rivera no era tanto el reordenamiento de la red de presidios sino la adecuación de las disponibilidades económicas de México a los usos 
reales que se daban a los situados enviados a Texas. Esta fue la base de la propuesta del virrey Casafuerte al rey el 26 de mayo de 1723, que aprobada el 19 de febrero del año siguiente daría lugar a la exitosa expedición de Rivera que se prolongaría desde noviembre de 1724 al invierno de $1727 .^{24}$

El aspecto económico, que no siempre se ha destacado, ni las dificultades inherentes a un sistema que incentivaba indirectamente la corrupción, estuvieron siempre en la mente de Rivera durante su viaje y en la posterior revisión que hizo de los presidios. El siguiente cuadro muestra los envíos de situados desde México capital a los cuatro presidios texanos antes del reglamento de 1729 inspirado por Rivera, así como los soldados que en teoría poseía cada presidio.

Cuadro 1. REMISIONES A LOS PRESIDIOS DE TEXAS ANTES DEL REGLAMENTO DE $1729^{25}$

\begin{tabular}{|c|c|c|c|c|}
\cline { 2 - 5 } \multicolumn{1}{c|}{} & NTRA. SRA. DEL PILAR & BAHIA ESPÍRITU SANTO & NTRA. SRA. LOS DOLORES & S. ANTONIO BEJAR \\
\cline { 2 - 5 } \multicolumn{1}{c|}{} & 93 SOLDADOS & 90 SOLDADOS & 25 SOLDADOS & 53 soldados \\
\hline 1716 & & & & \\
\hline 1717 & & & & \\
\hline 1718 & & & & \\
\hline 1719 & & & & \\
\hline 1720 & & & & \\
\hline 1721 & & & & \\
\hline 1722 & & & & \\
\hline 1723 & & & & \\
\hline 1724 & & & & \\
\hline 1725 & & 36.000 & 10.000 & \\
\hline 1726 & 43.850 & 36.600 & 10.000 & 21.200 \\
\hline 1727 & 47.000 & 36.600 & 10.000 & 21.600 \\
\hline 1728 & 47.000 & 60.067 & 10.000 & 39.629 \\
\hline 1729 & 79.595 & & & \\
\hline
\end{tabular}

FUENTE: AGI, México, Contaduría, 821, 822, 823, 824, 825. Pesos de a ocho.

Desconocemos, por el momento, los datos anteriores a 1726 en los que las cajas de Zacatecas y Guadalajara fueron las encargadas de los envíos del situado texano. No obstante, nada hace señalar que las cantidades fueran significativamente diferentes, ya que los envíos no se reglamentaron de una manera concienzuda hasta 1726, por lo que cabe pensar que antes de esa fecha, y debido a las enormes dificultades presupuestarias por las que pasaba el virreinato, es de suponer que incluso fuesen menores los envíos en dirección a Texas.

Sin embargo, lo significativo es que si hasta entonces estaba descentralizado el envío de los situados a las provincias internas, debió existir alguna razón por la cual la 
capital del virreinato optó por centralizar todo el gasto militar del norte de su frontera, en vez de continuar usando cajas reales más cercanas, y que sin duda generarían menor gasto, como las de Zacatecas o Durango. Creemos que la razón debió estar en el aumento de la corrupción y el descontrol que seguían a la estructura vigente, ya que desde México era mucho más fácil poder fiscalizar la labor de los funcionarios en las fronteras del virreinato, y no desde cajas reales cercanas a los presidios pero alejadas de las fuentes de control judicial, político y económico. El aumento de los gastos en el traslado de material y hombres quedaría, en este caso, compensado con el mayor control operativo y burocrático que desde la capital podía ejercer el propio virrey.

Es muy llamativa, en cualquier caso, la cantidad de dinero gastada en los presidios originarios de la Texas colonial española. Justo antes de que Rivera rediseñara el mapa de la frontera norte del virreinato, sólo la agreste y casi desconocida tierra de Texas generó un gasto a la hacienda real de 580.341 pesos. La cuantía se hace aún más significativa si se considera que está concentrada realmente en los cuatro últimos años anteriores al reglamento. En concreto 530.741 pesos para guarniciones teóricas de 261 soldados, es decir, más de 2.000 pesos por hombre en los cuatro años, y más de 400 al año. Es importante destacar que en el mismo período México enviaba 20.550 pesos a Manila en concepto de situado para una guarnición de 60 hombres, es decir, algo más de 300 pesos al año, y eso que la distancia que debía recorrer la plata hasta llegar a las islas Filipinas era 5 veces mayor. ${ }^{26}$ En 1726, por ejemplo, México envió a los Presidios de Barlovento unos situados por valor de 420.419 pesos, pero estas guarniciones eran básicamente la espina dorsal del sistema defensivo del caribe, pues englobaban las de La Habana, Santiago de Cuba, Puerto Rico, Santo Domingo y la fuerza de Araya en Cumaná, es decir, un conjunto de más de 2.000 hombres en recintos perfectamente fortificados y bien coordinados. ${ }^{27}$

Los gastos militares debían cumplir en cualquier ámbito los propósitos para los que están prefijados, y éstos, en la Texas de la primera mitad del siglo XVIII, estaban directamente relacionados con el control territorial, la pacificación y el mantenimiento de una paz que permitiera "salvar almas" de los indios. En este sentido, las cantidades aprontadas en Texas se nos antojan excesivas a la luz de los resultados prácticos, ya que de hecho, España, al menos hasta 1730, difícilmente tuvo el control efectivo del territorio comprendido entre los ríos Grande y Rojo, especialmente al norte y este de la zona controlada, supuestamente, por el presidio de San Antonio de Béjar. Si a esto se 
suma el hecho de que el número real de soldados era mucho menor, cabría preguntarse por la utilidad del sistema, o al menos por su idoneidad tal cual estaba configurado antes de la visita de Rivera. Es posible argumentar que los gastos eran necesarios dada la presión francesa hacia el oeste de Texas, y que debido a lo inhóspito e inculto del terreno, los sueldos debían ser más altos que en otras partes de los territorios españoles en Indias. Y esto es cierto, siempre y cuando se cumplieran con los cometidos mínimos, y siempre que el control fuese el apropiado al gasto generado. Sin embargo, las denuncias de descontrol, corrupción, cohecho y despilfarro eran tan habituales y estaban tan generalizadas a todos los niveles - empezando por los mismos capitanes de presidios -, que cabría preguntarse si, dado que esto parecía inevitable, no hubiera sido igualmente factible llegar a los mismos resultados - por otra parte muy pobres antes de 1730 - con un gasto sensiblemente menor.

La pregunta que no pocos historiadores se han hecho es cómo se canalizaba realmente el situado de Texas proveniente de la caja central de México, y de qué manera se gestionaba el dinero, ya que existen ciertas dudas en la manera en que presumiblemente se sostenían las guarniciones. Es sabido que los capitanes de presidios solían utilizar intermediarios en la capital - situadistas - encargados de transportar el dinero hacia la frontera, y que una parte del dinero no llegaba a las manos de los soldados en metálico, sino en mercancías. Ésta fue una práctica muy extendida en la primera mitad del siglo XVIII, pero que fue desfalleciendo hasta desaparecer casi por completo en las últimas décadas de la centuria. El problema de recibir parte de la paga en mercancías era obvio, ya que los capitanes suministraban a sus hombres determinados bienes a precios exorbitantes, quedándose ellos mismos con la diferencia. Esta práctica, claramente ilegal, fue motivo de no pocos juicios, querellas y problemas entre los soldados, sus capitanes y las autoridades virreinales.

Llegados a este punto es vital explicar que si bien estas prácticas eran habituales, no estaban dentro de la legalidad, ni eran común en toda la frontera. El soldado debía recibir el dinero en metálico; esa era la ley y las disposiciones eran claras a este efecto. Si durante las primeras décadas de la ocupación española de Texas se permitió parcialmente el pago en especie, hay que observarlo como una práctica extraordinaria, que gozaba de cierto respaldo de las autoridades de la capital, por la sencilla razón de que no había aún suficientes bienes que adquirir en una tierra recién ocupada y con escasa oferta de productos. Sin embargo, la ocupación de Texas, y esto ha pasado 
desapercibido para algunos historiadores, dio lugar a la extensión de haciendas y misiones entre el río Grande y el río Rojo a unos niveles realmente importantes, mientras que los contactos con los franceses instalados al este de la provincia, promovían todo tipo de intercambios. Esto debió contraer con el tiempo la necesidad de recibir parte de la paga en bienes, puesto que existía ya la posibilidad de adquirirlos en la zona, obviamente, a precios mucho más baratos que los provenientes de México. Por consiguiente, podemos afirmar que hasta mediados de siglo el porcentaje de situado recibido por los presidiales en forma de bienes fue probablemente alto, especialmente en los presidios más nororientales, aunque esta situación desembocó prontamente en un mayor control de los situados en metálico, tal y como demandaban los soldados.

Existe una tendencia por parte de cierta historiografía mexicana de negar la tesis de que hacia la frontera norte del virreinato se enviaban enormes cantidades de plata, la mayor parte de la cual estaba acuñada. La negación de esa circulación monetaria, extensible a la práctica totalidad del siglo XVIII, viene dada por la argumentación de que, sin bienes que comprar, los soldados no necesitaban dinero. Este argumento, en principio parcialmente lógico, no está, sin embargo, apoyado por pruebas firmes de que no existiera una circulación de numerario en la tierra fronteriza. Si bien hay algunos indicios de la escasez de plata, ésta se encuentra especialmente concentrada en las primeras décadas del siglo XVIII, y sólo están circunscritas a áreas muy concretas de la enorme franja fronteriza del norte novohispano. En líneas generales es admisible que una proporción de la paga de los soldados era suministrada en especie, como se ha indicado, lo cual, obviamente, disminuiría la circulación de plata, pero en absoluto la eliminaría. Además, la moneda que era desviada de las manos de los soldados no caía fuera de los circuitos monetarios, sino que seguía circulando, aunque en manos de las clases más poderosas: capitanes, misioneros y comerciantes.

Por tanto, se puede afirmar que el dinero circuló, y en grandes cantidades, por toda la frontera norte, y por Texas en especial, durante la práctica totalidad del siglo XVIII, aunque sufrió una lógica contracción durante las primeras décadas. Cuando la provincia estuvo fuertemente controlada, hacia mediados del siglo XVIII, el soldado demandaba dinero en metálico, porque ya existían garantías de poder adquirir bienes en una gran cantidad de misiones, haciendas y, especialmente, traficando con los franceses. ¿Acaso el comercio con los franceses de Natchitoches, en la orilla del río Rojo, y que era practica común desde el inicio de la Texas colonial, se hacía mediante el trueque? 
Los franceses, sus soldados y especialmente sus comerciantes no aceptaban otra cosa que la moneda española, el Real de a ocho, moneda con 16 gramos de plata prácticamente pura, tan apreciada en el mundo, que en los Estados Unidos, debido precisamente a la fuerte circulación de plata en la frontera colonial, se mantuvo como medio de pago legalmente aceptado hasta mediados del siglo XIX (i).

Por consiguiente, cuando hablamos de miles, decenas de miles e incluso centenares de miles de pesos en concepto de situados, debemos pensar también en las enormes toneladas de plata que, físicamente, se desplazaban desde las entrañas del virreinato por toda la frontera. Ahora bien, ¿Por qué existe aún la reticencia de algunos historiadores en aceptar que ese dinero efectivamente circulaba desde el virreinato hacia el norte? La explicación está en la tesis según la cual el virreinato de Nueva España suministró y mantuvo de forma más que sustancial no sólo las posesiones caribeñas (los famosos situados de barlovento), sino también gran parte del gasto metropolitano de España. Según esta tesis, el virreinato se habría convertido en el verdadero sostén del imperio, desplazando gran parte de sus recursos hacia España en detrimento de una coherente política de defensa interna, que forzosamente habría demandado fuertes inversiones de dinero. Es bien sabido que desde Nueva España se enviaron crecientes aportes fiscales a España y a Barlovento a lo largo del siglo XVIII, pero las cifras manejadas hasta ahora son, con certeza, exorbitantes, y la causa estriba, precisamente, en el uso de fuentes poco fiables o escasamente depuradas. En este trabajo, y en otros de similar naturaleza que se irán publicando, destacamos como elemento fundamental de nuestros análisis el hecho de que las cifras han sido extractadas partiendo del máximo rigor metodológico, limando los errores gruesos, y haciendo mucho más fiables y creíbles las cuentas públicas coloniales.

El desplazamiento de fuertes cantidades de plata acuñada o en pasta hacia la frontera septentrional no congenia muy bien con la mencionada teoría, porque pondría en evidencia que los flujos de metal desde el virreinato no siempre fueron en dirección este - hacia España y el Caribe -, sino también hacia el norte. Sólo entre 1730 y 1772, es decir, entre el reglamento de Rivera y el de Rubí, los presidios texanos absorbieron la cantidad de 3.197.195 pesos, y eso teniendo en cuenta que no tenemos datos de dos años, y sabemos que los presidios de Texas eran todos, exceptuando el de San Antonio y el de la Bahía, de escasa importancia. Incluso aceptando que una cuarta parte de ese dinero se pudo haber enviado en bienes y no en plata (porcentaje que he representado 
claramente al alza aunque albergo serias dudas de que fuera tan alto, especialmente después de 1750), el resultado final habría sido un considerable desplazamiento de plata hacia el norte, y esa masa monetaria tuvo, forzosamente, que circular por la provincia. $\mathrm{Y}$ Texas fue sólo un ejemplo, ya que los datos que poseemos indican con claridad que el gasto militar en todo el cordón presidial que discurría desde las Californias hasta el este de Texas fue excepcionalmente alto.

El trabajo con la contabilidad virreinal y la aplicación de una metodología de análisis completa nos ha permitido poder demostrar las afirmaciones anteriores. En efecto, el virrey de Nueva España, Casafuerte, informó al rey del estado de la visita a las provincias internas hecha por el brigadier Pedro de Rivera según real despacho de 19 de febrero de 1724, indicando que cuando llegó a este reino había 23 presidios con un costo anual de 444.883 pesos. El escrito añadía que esa cantidad era enviada en pesos de a ocho o plata en pasta, y procedía del grueso de la Real Hacienda. Los capitanes, como era costumbre, solían introducir ellos mismos los géneros que hacían falta ofreciéndolos a precios elevadísimos. ${ }^{28}$ Por consiguiente, vemos que incluso en un informe oficial se hacía mención expresa de la manera en que eran pagadas las guarniciones, es decir, en metálico y en plata, aunque también se decía que los capitanes "secuestraban" parte de ese dinero para intercambiarlo por bienes.

Los rublos de la contaduría de la caja de México son incluso más explícitos, pues en ellos aparecen con certeza y claridad la cantidad de dinero y la forma en que eran efectivamente enviados hacia la frontera norte. A modo de ejemplo, se indicaba que en 1711 se pagó al coronel visitador de los presidios, Juan José Mazoni, "1.095 pesos en reales" y a los apoderados y 40 soldados del presidio de Cuencame, "44.079 pesos en plata, de los cuales 42, 715 pesos en plata de toda su ley y 1.284 en reales". ${ }^{29}$ Las cuentas son iguales para el resto de los presidios, y en todas se especifica que los pagos se hicieron en plata en toda su ley o en reales, entregándose en mano a los correspondientes situadistas, o bien directamente enviados. Según una Junta de Hacienda de tiempos del virrey duque de Alburquerque, se ordenó por despacho de 6 de marzo de 1706 que "todas las pagas que hiciésemos fuesen en reales y no habiéndolas en plata a toda su ley sin la quiebra del rescate", por este motivo, el situado del presidio de la provincia de Nuevo México estaba antes de esa fecha por los 100 hombres en 45.764 pesos al pagarse con el rescate de 4 tomines menos en cada marco de plata, pero desde 1706 el situado queda fijado en 43.111 pesos. $^{30}$ 


\section{Las repercusiones del plan de Rivera}

Los cambios introducidos por Rivera realmente no afectaron tanto a Texas como se ha argumentado. Su informe especifica con claridad el lamentable estado de todos los presidios texanos, y como en algunos la miseria se había generalizado. ${ }^{31}$ Su reglamento, de 1729 , más que modificar el sistema presidial, lo que hizo fue ajustarlo a la realidad económica y geoestratégica de su época. ${ }^{32}$ En lo que a Texas se refiere, las guarniciones se redujeron de número en los tres presidios que se mantuvieron (Los Adais, San Antonio y La Bahía), en número de 60 hombres, pero esta disminución de la fuerza efectiva no fue baladí, porque lo que la mayoría de los autores olvidan es que muy rara vez estos presidios tenían más del $50 \%$ de su fuerza efectiva. Se eliminó un presidio, el de Los Tejas, o Ntra. Sra. de los Dolores, pero era porque apenas existía sobre el papel. Por tanto, la lógica de Rivera fue ¿Por qué pagar más dinero por unos hombres inexistentes en la práctica si ese dinero va en realidad a los bolsillos de los corruptos capitanes de presidio y sus "colaboradores" franciscanos? De hecho, el poderoso grupo franciscano del Colegio de Santa Cruz de Querétaro, sin duda el más influyentes de los dos colegios franciscanos destinados a Texas (el otro, el de Nuestra Señora de Guadalupe de Zacatecas, apenas tenía influencia por estos años), apenas si pudo sustraerse al fácil negocio de la corrupción. El gobernador Manuel de Sandoval, que lo había sido en la época inmediata a la visita de Rivera, tuvo escandalosos negocios apoyándose por acción u omisión en los padres franciscanos, e incluso con la anuencia indirecta del propio virrey. Su sucesor, Carlos Franquis Benitez de Lugo, llegó incluso a redactar un voluminoso informe al marqués de la Ensenada en la que daba cumplida cuenta de la difícil situación financiera en que se encontraba la provincia, lo cual demostraba que el hecho de poseer situados elevados no garantizaba una correcta administración militar de los presidios, sino precisamente una adecuada canalización y control de dichos recursos. ${ }^{33} \mathrm{Y}$ no cabe duda que las acciones de Sandoval ya se venían produciendo desde hacía décadas ya que la tierra de frontera, sin control, era un inestimable caldo de cultivo a las prácticas ilegales. El reglamento de Rivera actuaba precisamente en esta dirección.

De hecho, el reglamento de Rivera y sus comentarios fueron profusamente usados incluso varias décadas después de su aplicación, y los ataques que ya en época 
contemporánea generaron sus recortes presupuestarios hay que enmarcarlos, precisamente, en la disputa política por el control de la masa monetaria que discurría hacia Texas. ${ }^{34}$ En nuestra opinión, carecen de sentido los argumentos contra Rivera que indican que, mientras el reglamento estipulaba recortes, la corona conforme avanzaba el siglo, iba creando nuevos presidios y atendiendo, cuando podía, a las demandas de nuevos asentamientos. No se tiene en cuenta que la misión de Rivera y el reglamento de 1729 tenían un objetivo muy definido y limitado en el tiempo. Rivera no podía saber, en 1729, la futura política adoptada por los virreyes novohispanos, como tampoco podía saber el nivel de gasto o la disponibilidad de recursos treinta años después de los hechos. Él se limitó a aplicar el sentido común que, como militar, le indicaba que o era sostenible mantener un gasto que, sencillamente, no redundaba en ningún beneficio palpable a la corona española.

Es más, el problema no fue de recortes presupuestarios, sino de control del cohecho y del contrabando que ejercían los mismos capitanes, y en este sentido Rivera jamás recibió instrucción alguna de cómo atajarlo. De hecho, la corrupción siguió imperando, a pesar de los recortes de dinero. Uno de los casos más sintomáticos, y no muy en profundidad estudiados, fue el del gobernador de Texas que precisamente tuvo que aplicar en primer lugar el reglamento de Rivera.

El virrey marqués de Casafuerte nombró en 1733 a Manuel Sandoval como gobernador de la provincia. Pese a que el nuevo reglamento obligaba al gobernador de Texas a residir en el presidio de Adais, se mantuvo todo el tiempo en el de Béjar. Las noticias de la corrupción y la desobediencia de este gobernador llegaron incluso a la misma capital del virreinato, y el virrey se vio obligado a tomar cartas en el asunto, especialmente cuando se tuvo noticias de la implicación de franciscanos en los sobornos y robo del situado. Carlos Franquis Benítez de Lugo tomó posesión del cargo como nuevo gobernador el 26 de septiembre de 1736. El 28 de abril de 1737 Franquis detuvo con grilletes incluso a Sandoval en el presidio de Bejar, una vez que se comprobó que éste no había pagado las libranzas de los situados de este presidio. Se acusó a Sandolval de haber permitido el traslado del presidio francés de Natchitoches a suelo español, habiendo aceptado sobornos y habiendo desviado dinero de los presidiales. Se le acusó formalmente de siete cargos criminales en el juicio de residencia, entre ellos haber suministrado a los soldados géneros nobles en sus pagas pese a que lo prohibía el reglamento. Fueron presentados los cargos formalmente el 4 de agosto de 1738. El 28 
de marzo de 1740 se le absorbió de los cargos más importantes, y sólo se le multó con 500 pesos por las faltas menores referentes a las altas y bajas de los soldados a su cargo. El 13 de enero de 1741 renunció definitivamente Franquis al gobierno de Texas, siendo virrey el Duque de la Conquista, pero a instancias de Franquis y en vista de la gran cantidad de testigos que se aportó, reabrió el juicio contra Sandoval y, detenido, se le detuvo en prisión por decreto de 17 de septiembre de $1740 .{ }^{35}$

¿Cuál fue la evolución del gasto militar y la situación de los presidios de Texas en los años posteriores a la aplicación del reglamento de Rivera? Los datos, ahora ya centralizados desde la caja de México, indican que la supuesta reducción del gasto en los presidios texanos era más ficticia que real, puesto que a lo reglamentado había que añadírsele las siempre inevitables remisiones extraordinarias por motivo de acciones bélicas, campañas o retrasos. Con sólo tres presidios para defender toda la enorme provincia de Texas, y hasta 1750, en que se creó el presidio de San Javier, las arcas mexicanas habían suministrado a Texas la nada despreciable cifra de 981.538 pesos desde 1730. 
Cuadro 2. REMISIONES A LOS PRESIDIOS DE TEXAS ANTES DEL REGLAMENTO DE 1772

\begin{tabular}{|c|c|c|c|c|c|c|}
\hline & ADAIS & $\begin{array}{l}\text { ESPIRITU } \\
\text { SANTO }\end{array}$ & S. ANTONIO BEJAR & S.AGUSTIN AHUMADA & DE LAS AMARILLAS & SAN JAVIER \\
\hline 1730 & 40.205 & 15.118 & 17.005 & & & \\
\hline \multicolumn{7}{|l|}{1731} \\
\hline 1732 & 21.785 & 15.354 & 3.915 & & & \\
\hline 1733 & 27.265 & 15.845 & 17.005 & & & \\
\hline \multicolumn{7}{|l|}{1734} \\
\hline 1735 & 27.265 & 15.845 & 32.991 & & & \\
\hline 1736 & 27.265 & 15.845 & 17.005 & & & \\
\hline 1737 & & 31.690 & 17.005 & & & \\
\hline 1738 & 26.552 & & & & & \\
\hline 1739 & 25.264 & 15.844 & 17.005 & & & \\
\hline 1740 & 25.264 & 15.844 & & & & \\
\hline 1741 & 13.132 & 7.922 & 8.402 & & & \\
\hline 1742 & 13.132 & 7.922 & 8.402 & & & \\
\hline 1743 & 52.530 & 15.845 & 17.205 & & & \\
\hline 1744 & 27.265 & 15.845 & 24.450 & & & \\
\hline 1745 & 26.240 & 15.845 & 19.564 & & & \\
\hline 1746 & 26.265 & 36.510 & & & & \\
\hline 1747 & & & 17.005 & & & \\
\hline \multicolumn{7}{|l|}{1748} \\
\hline 1749 & 26.265 & 15.845 & & & & \\
\hline 1750 & 52.110 & 15.645 & 34.011 & & & \\
\hline 1751 & 27.345 & & & & & 26.665 \\
\hline 1752 & 27.345 & 31.690 & 17.005 & & & \\
\hline 1753 & & & 17.006 & & & 11.625 \\
\hline 1754 & 55.950 & 31.690 & 30.810 & & & 20.665 \\
\hline 1755 & & & & & & 20.665 \\
\hline 1756 & 55.530 & 31.690 & 15.005 & & & \\
\hline 1757 & 27.765 & 15.845 & 15.005 & 15.845 & 41.619 & \\
\hline 1758 & 27.765 & 22.164 & 7.595 & 22.065 & 40.360 & \\
\hline 1759 & 27.765 & 28.429 & 7.595 & 16.065 & 45.842 & \\
\hline 1760 & 27.765 & 29.014 & 7.595 & 19.065 & 93.952 & \\
\hline 1761 & 27.765 & 19.645 & 6.595 & 19.065 & 11.644 & \\
\hline 1762 & & 19.645 & 7.595 & 6.000 & 69.445 & \\
\hline 1763 & 27.765 & & 400 & 19.065 & 800 & \\
\hline 1764 & 27.765 & 39.290 & 16.725 & 16.065 & 40.760 & \\
\hline 1765 & 27.765 & & & 19.245 & 40.760 & \\
\hline 1766 & 27.065 & 19.645 & & 18.945 & 15.760 & \\
\hline 1767 & & & 8.595 & & 65.760 & \\
\hline 1768 & 27.625 & 19.645 & & 6.000 & & \\
\hline 1769 & 11.742 & 38.696 & 31.709 & 44.646 & 80.310 & \\
\hline 1770 & 45.982 & 20.413 & 14.858 & 33.992 & 34.019 & \\
\hline 1771 & 34.140 & & 34.142 & 5.651 & 32.148 & \\
\hline 1772 & 800 & 37.704 & 19.092 & 29.378 & 33.590 & \\
\hline
\end{tabular}

FUENTE: AGI, México, Contaduría, 821, 822, 823, 824, 825, 826, 827, 828. Pesos de a ocho. 
Durante la década de 1730 y hasta 1745 los problemas militares fueron permanentes. Las asignaciones que recibían los presidios de Texas, aunque eran nominalmente altas, no fueron suficientes para mantener a las guarniciones en perfecto orden de equipamiento y entrenamiento. San Antonio de Béjar recibía un situado de 17.000 pesos anuales para una guarnición de unos 45 hombres, la mayoría de los cuales vivían con sus familias. ${ }^{36}$ Hasta 1730 , es decir, justo hasta después de las recomendaciones de Rivera, el situado de este presidio era de 22.000 pesos, una cantidad respetable teniendo en cuenta las penurias financieras en estos lugares. ${ }^{37} \mathrm{El}$ otro gran presidio de Texas, el de Nuestra Señora de Loreto (o presidio de La Bahía), sufrió una reducción parecida pasando de 36.000 pesos a algo más de 15.000 a partir de 1730.

El plan de Rivera, que como se ha visto, pretendía concebir una reducción de gastos con evidentes beneficios para las arcas reales, pero mejorando la disposición de los presidios y especialmente su administración interna, falló lamentablemente debido a que no se articularon desde el virreinato las medidas pertinentes para que así fuera. La reducción de un presidio en Texas se ha visto que no hacía disminuir espectacularmente el gasto, pero al no aplicarse un férreo control sobre el situado y su distribución, al final el dinero acababa en las mismas manos de siempre: capitanes corruptos, gobernadores ávidos de poder y riqueza, y franciscanos que miraban hacia el otro lado a cambio de un poco de dinero y mayor control directo sobre las misiones. Al contrario, al comenzar la década de 1740, las guarniciones tuvieron enormes problemas para contener a los indios ya que la falta de preparación y de dinero había rebajado notablemente la calidad de los soldados. Además, pronto se vio que el este de Texas se encontraba desatendido en la práctica y que los presidios de San Antonio y Nuestra Señora del Pilar difícilmente podían sostener el territorio comprendido entre los ríos Rojo y Neches con las muy escasas misiones que allí se encontraban. Por este motivo pronto se empezó a pensar seriamente en extender la influencia sobre Texas con una mayor presencia tanto al norte de San Antonio como hacia el este. Después de no pocas discrepancias y discusiones entre los gobernadores de Texas, el virrey y los misioneros se pudieron crear entre 1746 y 1749 nuevas misiones al noreste de San Antonio en torno al río San Gabriel. Para su protección se vinculó una pequeña escolta de soldados, que se mostró insuficiente para la lucha contra los apaches, de manera que en 1751 se fundó un nuevo presidio, el de San Francisco Javier, con una guarnición teórica de 51 soldados y un situado de 20.665 
pesos. ${ }^{38}$ Sin embargo, la fundación de estos asentamientos no trajo la paz al territorio. Pronto se vio que la anarquía y desorganización reinarían entre los soldados presidiales y las misiones circundantes, sin duda motivados por la desaprensiva y corrupta actitud del capitán del nuevo presidio, Felipe de Rábago. ${ }^{39}$ Así, en medio de escándalos continuos, violaciones de indias e incluso asesinatos entre los propios soldados, en 1755 tanto las misiones como el presidio desaparecieron y sus recursos financieros y humanos fueron destinados a otros lugares más productivos. Resulta curioso que la pretendida "draconiana" reducción de Rivera y su reglamento obligara a crear un presidio que provocó el despilfarro de casi cien mil pesos en apenas cinco años de existencia.

Al tiempo que se realizaban estos cambios, José de Escandón proyectó la colonización de toda la costa del seno mexicano y la creación de una nueva provincia que recibiría el nombre de Nuevo Santander. Su extensión iría desde la bahía de Matagorda, en la parte sur de Texas, hasta Tampico, de manera que en esencia el proyecto no afectaba demasiado a las misiones o presidios tejanos. ${ }^{40}$ La actuación más destacada sobre los enclaves en Texas fue el traslado en 1749 del presidio de Nuestra Señora de Loreto desde el río Guadalupe al río San Antonio, a su izquierda. Su cercanía al presidio de San Antonio y su localización más próxima a las numerosas misiones estacionadas a lo largo del río del mismo nombre facilitaran el desarrollo del presidio y su organización.

Por otra parte, como medida para cerrar las incursiones indias desde el norte de San Antonio, y en concreto a través del río San Sabá, se fundó en la primavera de 1757 en esa zona una misión y un presidio que recibiría por nombre San Luis de las Amarillas. El objetivo de este presidio era tanto defensivo como ofensivo, por lo que su guarnición estuvo compuesta por 100 soldados y el situado se elevó a 40.000 pesos. ${ }^{41}$ La fundación de este destacamento militar demostró ser un acierto, ya que tan sólo un año más tarde la misión fue atacada por varios cientos de indios, dando muerte a decenas de personas, y los que se salvaron lo consiguieron gracias a la protección otorgada por el presidio. ${ }^{42}$ Una expedición de castigo lanzada en 1759 , que se prolongó un año más, costó una gran suma de dinero pero apenas dio fruto, ya que justo al norte del río San Sabá encontró un asentamiento francés fuertemente armado, que no se pudo conquistar. La fuerte y agresiva presencia india en los contornos del río San Sabá determinó que las misiones proyectadas allí no se llevaran a cabo, y que la única 
existente desapareciera al poco tiempo. El presidio continuó algunos años pero sólo para ir languideciendo lentamente. En el este de Texas y en general en todo el territorio, el antiguo reglamento había demostrado para esas fechas ser un completo fracaso. La subida de precios desde 1729 había provocado la ruina de los presidios y que sus capitanes no pudieran hacer frente a los pagos debido a la alta inflación de una zona en permanente estado de guerra. ${ }^{43}$

En el este de Texas y en las cercanías de la desembocadura del río Trinidad se estableció en 1756 una misión junto a un presidio muy cercano, llamado San Agustín de Ahumada. Su guarnición contaba con 31 soldados y un situado de 19.000 pesos. ${ }^{44}$ Los indios lugareños eran también bastante belicosos y además contaban con bastante apoyo de los franceses que se iban infiltrando desde el este de Texas hasta las costas del golfo mexicano. La situación cambió cuando en 1762 esta zona dejó de ser la frontera natural entre Texas y la Luisiana francesa, ya que en esa fecha el territorio francés pasó a dominio español, lo que hizo poco viable el mantenimiento de su costosa guarnición. A finales de la década de 1760 el presidio acabó siendo trasladado de sitio.

A mediados del siglo XVIII, por tanto, la situación de los presidios de Texas era muy variada. La evolución en las relaciones con los indios, el elevado número de misiones y su mayor cercanía al centro de México hicieron que el territorio entre los ríos Colorado y San Antonio tuviera un favorable crecimiento y una relativa prosperidad y tranquilidad. Claramente esta zona había dejado de ser un lugar de frontera, agreste y peligroso, y por ese motivo se convirtió en el centro de la mayoría de las expediciones hacia otros lugares de Texas. Los presidios de San Antonio de Béjar y de Nuestra Señora de Loreto (La Bahía) incrementaron claramente la seguridad del territorio y acabaron siendo el centro principal desde donde los soldados se movilizaban hacia otros presidios en épocas de crisis o para determinadas operaciones de castigo. Además, su presencia limitó mucho el posible empuje e influencia franceses en el golfo de México.

Resulta especialmente llamativo el elevado coste total de esas pequeñas guarniciones que rara vez estaban al completo de efectivos. En efecto, entre 1740 y 1760 los situados totales de los presidios de Texas fueron de 1.709 .888 pesos, lo que supone una media por presidio de 244.270 pesos. Si tenemos en cuenta que los presidios de San Agustín de Ahumada, San Javier y San Luis de las Amarillas resultaron un completo fracaso y acabaron desapareciendo en un plazo no superior a diez años, 
podemos aseverar que el costo fue especialmente alto y escasamente productivo. Estos tres presidios supusieron un gasto para las arcas mexicanas de 365.433 pesos (el $21 \%$ del total arriba señalado), para unos resultados parcialmente negativos. Con esta cantidad se podía haber sufragado un año completo del Fijo de La Habana con todos sus efectivos o construido un nuevo Santísima Trinidad de 130 cañones en el astillero habanero. La comparación en este caso no es baladí, porque permite comprobar el nivel de esfuerzo de las arcas mexicanas precisamente en un período en que sus peticiones eran muy altas desde todos los presidios y guarniciones del seno mexicano dependientes de ellas. Las tierras de Texas eran en realidad lugares muy desconocidos para los españoles, inhóspitos y peligrosos, y aportaban ciertamente muy poco a la preponderancia española en América. La construcción de presidios en tierras de frontera, alejadas de toda civilización, difícilmente sostenibles y extremadamente costosas era una tarea digna de encomio y que decía mucho de los gobernadores que las vigilaban y de los virreyes que aportaban el dinero para una aventura siempre de éxitos imprevisibles.

Resulta curioso observar cómo se encontraban dispuestos geográficamente los cuatro presidios principales que se mantuvieron activos durante este período. San Juan Bautista de Río Grande estaba ubicado en el extremo occidental de la provincia de Texas, lindando con Nuevo México como puerta natural hacia el interior tejano desde esa provincia; Nuestra Señora de Loreto (La Bahía) se situaba en la misma costa del golfo de México; San Antonio Valero cerca del nacimiento del río del mismo nombre, hacia el centro de la Texas conocida y bien explorada hacia mediados de siglo; mientras que por último Nuestra Señora del Pilar se encajaba en el sector más oriental de la provincia, cerca del curso medio del río Rojo, situado como puerta natural de la provincia de Luisiana. Es decir, casi siguiendo unos ejes norte-sur, este-oeste, los presidios significativos y que pervivieron en sus misiones defensivas se enmarcaban realmente en los sectores mejor explorados y más importantes para los intereses españoles a mediados de siglo desde el punto de vista geoestratégico. Y en estos presidios el situado suministrado durante este período fue de 1.344 .455 pesos, lo que se antoja una cantidad muy importante, especialmente porque aún no se había entrado en la etapa expansiva de gastos militares durante el reinado de Carlos III, sobre todo a partir de 1780 . 
Es de notar que ninguno de los situados durante este período fue regular en su cuantía, algo que era común a la inmensa mayoría de los situados que conocemos en el siglo XVIII. Esta irregularidad indica claramente su dependencia de las coyunturas externas, especialmente relacionadas con nuevas exploraciones hacia otras partes de Texas, o bien expediciones de castigo contra los indios lugareños. Esto, unido a la cambiante naturaleza de las guarniciones, que rara vez estaban al completo, provocaba que los situados rara vez pudieran mantenerse con unas cantidades permanentes a lo largo del tiempo. Sin embargo, lo que más llama la atención del estudio de estos situados es la tendencia absolutamente diferenciada e incluso divergente entre las distintas guarniciones y presidios. Es perfectamente visible que las cuantías de cada enclave fueron distintas e independientes de las demás, sin tener ninguna relación cuantitativa o a su periodicidad. Esto indica que los distintos presidios tejanos estaban sujetos a sus propias evoluciones y coyunturas, tanto económicas como monetarias, y que la política del virreinato mexicano no era homogénea para con la provincia de Texas. Es decir, que los virreyes enviaban las cantidades de dinero a los principales presidios atendiendo a necesidades concretas y a peticiones determinadas al no existir en absoluto una política global con respecto a Texas. Era realmente lo característico de las guarniciones de frontera, aunque nada bueno para ellas. Si la corona hubiera tenido una deseable política de conjunto para esta provincia o cualquiera otra lindante con sus posesiones conocidas, el envío de situados hubiera sido más o menos común a todos los presidios, aunque salvando, obviamente, las diferencias cuantitativas entre unos y otros. Pero, al actuar en función de los intereses locales, se creaban situaciones discriminatorias entre presidios que rara vez tenían relación directa con la realidad. Cuando las líneas de situados son tan divergentes en un mismo espacio geopolítico, quiere decir que no había una idea clara de lo que hacer en ese espacio, lo que derivaba en una pérdida de importancia del ámbito que se pretendía apoyar con las inyecciones de capital por la vía de los situados. Parte del problema era, precisamente, la inexistencia de un presupuesto de defensa predeterminado, y por ende una falta de medios económicos previos destinados a fines concretos. Como la evolución de las rentas era coyuntural y sujeta a múltiples cambios, la disponibilidad de dinero para el situado era, por consiguiente, muy cambiante.

La consecuencia de todo esto fue que presidios que debían haber acabado imponiéndose a otros por su situación geográfica o por intereses militares acabaron 
desapareciendo ante la falta de una política común y ordenada para todo un territorio. Esto fue lo que le pasó al presidio de San Luis de Las Amarillas, que posiblemente era el que gozaba de una situación geográfica y militar más destacada en el centro de Texas, pero que acabó en desastre debido al escaso interés común de las distintas partes implicadas: virrey, gobernador de Texas, capitanes de presidios y religiosos fundadores de misiones.

La política de expansión y exploración de los virreyes de Nueva España en esta provincia se basó fundamentalmente en su capacidad financiera para poder sufragar en momentos determinados nuevas exploraciones e intentos de frenar a los franceses de la Luisiana. En cambio, este dinero no ayudó equilibradamente a extender la presencia hispana en Texas de una manera firme y permanente, sino que se vio sacudida por los vaivenes externos. Texas en 1760 no era un territorio bajo control absoluto de España, sino la unión de diversos presidios salpicados por misiones que mal que bien tenían que subsistir con los situados de México y con sus propios medios. Esto hacía que la vida de frontera no sólo fuese dura, sino también muy ingrata para quienes exploraban y fundaban estas misiones y presidios. Al carecer de una política de conjunto, los situados se convertían realmente en pequeñas dádivas que servían básicamente para mantener en pie a las esqueléticas guarniciones tejanas, pero que no estaban pensadas para crear una política de defensa común para todo un territorio.

\section{Las reformas del marqués de Rubí}

El cómputo absoluto de los gastos militares, o más bien de los situados enviados desde México a los diferentes presidios texanos entre 1730 y 1772, año de aplicación del nuevo reglamento de Rubí, resulta verdaderamente espectacular: nada menos que 3.197.195 pesos $^{45}$ que, realmente, se concentraron en los presidios clásicos. Sin embargo, casi trescientos mil pesos fueron a parar al presidio de San Agustin de Ahumada, y más de seiscientos mil al de San Luis de las Amarillas, ambos destinados a desaparecer en breve. Resultaba claro que algo no funcionaba bien: el reglamento de Rivera hacía tiempo que se había dejado de aplicar, aunque buena parte de sus recomendaciones se continuaban, al menos en privado; por su parte, se creaban presidios nuevos que rápidamente entraban en colapso pese a las enormes cantidades de dinero que llegaban, todo ello en un ambiente que, ni mucho menos, había eliminado el 
persistente tufo de corrupción. El mismo virrey, marques de Cruillas, se vio envuelto en estos asuntos, ya que el visitador militar, el teniente general Juan de Villalba, llegado a México en 1764, le había criticado abiertamente su dejadez para con los presidios de la frontera, llegando incluso a acusarle de haberse embolsado parte de los fondos. ${ }^{46}$

Esta fue una de las razones que empujaron al Marqués de Cruillas a seleccionar al Marqués de Rubí para su famosa expedición, ya que quería demostrar lo que se había hecho en la frontera, al tiempo que descargaba responsabilidades en los capitanes de los respectivos presidios. La idea era básicamente la misma que con Rivera, a saber, realizar un estudio detallado de la distribución y situación de los presidios para posteriormente aplicar las mejoras necesarias fundamentalmente por la vía de la reglamentación nueva. La expedición partió en la primavera de 1766. Después de más de un año y del largo dictamen de Rubí de 1768, se iniciaron los estudios que derivarían en un nuevo reglamento.

Tras realizar un viaje muy similar al de Rivera, se encontró con veintitrés presidios en la frontera, es decir, seis más que los dejados por Rivera. ${ }^{47}$ En ese momento la fuerza total de las guarniciones era de 1.161 hombres y más de 453.503 pesos de costo, lo que significaba sin duda una pesada carga para las arcas de la tesorería mexicana. ${ }^{48}$ Rubí propuso la disminución del gasto hasta los 373.000 pesos anuales, siguiendo en este caso una política similar a la de Rivera treinta años antes. ${ }^{49}$ El nuevo Reglamento, surgido de las ideas preconcebidas de Rubí, pero también de los informes de Hugo O’Conor y del visitador José de Gálvez, vio la luz finalmente en 1772. Primeramente, los capitanes de presidios fueron despojados del control de los situados, pasando a ser administrados directamente por oficiales reales, con lo que se evitaba de un plumazo, al menos sobre el papel, el uso fraudulento de los dineros. Se redujo la línea defensiva a sólo quince presidios, acercándolos a las ciudades más importantes que debían suministrarles tanto los productos como los situados. Con este reglamento, México dejó de ser el suministrador directo de situados, siendo éstos enviados por las cajas de Chihuahua, Sonora y San Luis de Potosí.

El presidio de los Adais había demostrado a Rubí ser un foco permanente de problemas, básicamente por su cercanía a los franceses. Llegó a descubrir que su comandante había desviado gran parte del situado en su propio beneficio y vendido los mejores caballos a los franceses: tal situación era inadmisible. Poco después, en 1773, se abandonaba definitivamente uno de los presidios más antiguos de Texas, pero 
también de los más problemáticos. El presidio de San Agustín de Ahumada también fue suprimido ante el elevado costo de sostener una guarnición exigua y lamentablemente proclive, a causa de los manejos de sus comandantes, a llegar a acuerdos con los franceses. Con la supresión de ambos presidios, en 1773, la capital de la provincia de Texas pasó a la ya importante población y presidio de San Antonio de Béjar, quedando únicamente ya otro presidio en el territorio, el de la Bahía, en la costa, con el único fin de controlar el contrabando y toda la banda interior del seno mexicano en aquella región.

En la posible pérdida de la importancia de Texas como línea de frontera, influyó decisivamente la adquisición por parte española de La Luisiana, cedida por los franceses tras la paz concertada por ambas potencias con Inglaterra en 1763. Al desaparecer la frontera natural con los franceses en el río Rojo, que durante años había dado de comer a los soldados del este de Texas gracias al contrabando y al permitido, aunque ilegal, comercio con los franceses, España dejó de interesarse por Texas como una provincia de decisiva importancia militar. Ahora el enemigo, los ingleses, estaban mucho más hacia el este, y Texas no tenía frontera con La Florida británica. Por tanto, el plan de Rubí encajaba perfectamente en el diseño de la nueva política de defensa de la frontera del septentrión, y cabe incluso incluirla en la misma línea de las reformas vitales que emprendieron el visitador militar Juan Villalba ${ }^{50}$ en México en la década de 1760 y Alejandro O’Reilly en Cuba por los mismos años. ${ }^{51}$

Incluso tras los recortes en la provincia de Texas, y hasta finales de siglo, los dos únicos presidios más los otros dos que fueron suprimidos en 1773, aunque debido al traslado de hombres y material, siguieron recibiendo dinero durante 3 ó 4 años, supusieron para las arcas de México y principalmente para las de San Luis de Potosí, responsable de los situados de San Antonio y La Bahía, más de 1.088.145 pesos, pagados todos en moneda. ${ }^{52}$

¿Cómo encaja la teoría de la dependencia metropolitana de Nueva España esta transferencia de millones de pesos hacia el norte del virreinato? Los datos que poseemos sobre las transferencias de dinero hacia el cordón presidial entre 1772 y 1800 muestran el envío, efectivo, de varios millones de pesos. ${ }^{53}$ La política española, especialmente con el gobierno del Ministro de Indias José de Gálvez, quien conocía de primera mano las posibilidades reales de Nueva España tras su visita en los años sesenta, parece que primó la transferencia de metales a España y la adopción de una fuerte política de 
autodefensa en Indias. Sin embargo, los gastos militares en Caribe (Cuba principalmente, con su apostadero al frente), en el septentrión e incluso en la frontera sur del virreinato indican que la contracción del gasto no se percibió de manera notable. La guerra de 1779 a 1783 evidenció las enormes posibilidades del virreinato en orden a sostener la defensa colonial, e incluso a acometer impresionantes ofensivas, como la conquista de Mobila, Pensacola y las Bahamas, lo que supuso, sin duda, la mayor victoria militar española sobre los ingleses desde el sonado fracaso ante las murallas de Cartagena en 1741.

Por consiguiente, si bien en Texas se produjo un lento y obvio declinar, no se puede decir lo mismo del resto de los sectores de la administración militar que dependían del virreinato, y por consiguiente cabe preguntarse si, efectivamente, las transferencias coloniales de plata a la península fueron tan importantes como se dicen. El hecho, innegable, es que Nueva España dispuso de suficientes recursos para aprontar con relativas garantías la defensa de su entorno geoestratégico hasta principios de siglo XIX, y en ningún caso el gobierno español desatendió las obligaciones coloniales a favor de una transferencia masiva de capital hacia España. El gasto militar así lo atestigua y no poseemos ninguna prueba documental que indique que los virreyes recibieron órdenes directas de Madrid de desviar fondos para sostener a la metrópoli.

Texas, obviamente, había modificado su propia misión militar, pero si bien el reglamento de Rubí supuso un recorte presupuestario importante, en cambio trajo consigo la modernización de sus estructuras de control sobre el dinero destinado al ejército. Sin duda, el que los capitanes de presidios, antaño poderosos, perdieran la capacidad de hacerse cargo de los situados los puso en el centro de toda crítica, y demuestra que el problema en Texas no era de dinero, sino de falta de gestión de los recursos.

Habría, sin embargo, que esperar a los mejores tiempos de las reformas de Carlos III y a la creación de la Comandancia General de las Provincias Internas del norte de Nueva España en 1776 con José de Gálvez para que Texas fuese verdaderamente una entidad geopolítica con dimensiones propias y con un sistema defensivo organizado y estructurado de manera eficaz y efectiva. 


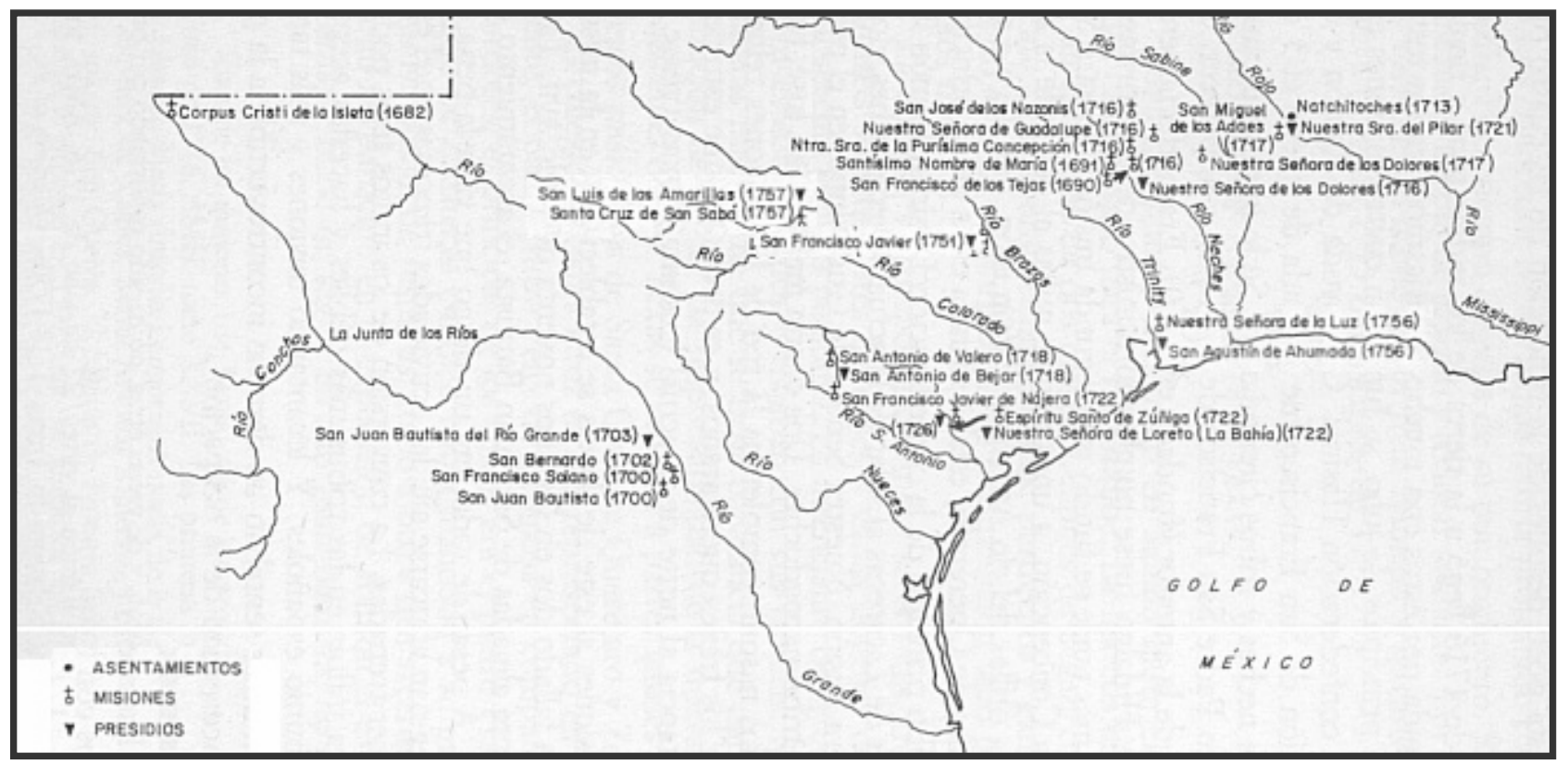

Fuente: Donald Chipman, Texas en la época colonial, Madrid, Mapfre, 1992, p. 95.

ALVAREZ, José Manuel Serrano e KUETHE Allan J. Methodological and economic contributions to the Texas presidiary system, 1720-1772. História, São Paulo, v. 25, n. 1, p. 70-99, 2006.

Abstract: This article tries to show not only new methodological aspects of studies about military financing in Indias but also tries to answer some important questions concerning to military fiscalization of Texas province in the eighteen century. It is well known the contribution of Rivera and Rubí on the frontier history: two excellent regulations in 1729 and 1772. However, no study has tried to show the real economic impact over the frontier (soldiers, missionaries, presidios), and only a few studies have availed themselves of cajas reales to analyse the way in which Mexico supported the northern frontier. This study is the first one which tries to give a logical and historical explanation about these matters: cost of the presidios in Texas during XVIII century, money circulation and problems about the applications of the 1729 Rivera regulation.

Keywords: Texas, New Spain, Presidiary System.

Artigo recebido em 09/2006. Aprovado em 10/2006.

\section{NOTAS}

\footnotetext{
* Universidad de Sevilla, España.

** Universidad Texas Tech, Lubbock, EUA.

${ }^{1}$ Por cuestiones de espacio no se pueden citar todos los trabajos que merecen serlo, pero destacamos por su profundidad los de BANNON, John F., The Spanish Borderlands Frontiers, 1513-1821. Holt, 1970;
} 
WEBER, David J. The spanish frontier in North America. Yale University Press, 1992; Donald E. Chipman, Texas en la época colonial, Mapfre, 1992; MOORHEAD, Max L. The Presidio: Bastion of the Spanish Bordelands. University of Oklahoma Press, 1975; JACKSON, Jack. Los Mesteños: Spanish Ranching in Texas, 1721-1821. Texas A\&M University Press, 1986, y Imaginary Kingdom. Texas as seem by Rivera and Rubi Military expeditions, 1727 and 1767, Texas State Historical Association, 1995; WORCESTER, Donald E. The Texas Longhorn: Relic of the Past, Asset for the Future. Texas A\&M University Press, 1987; así como el americanista español Luis Navarro, Don José de Gálvez y la Comandancia General de las Provincias Internas del Norte de Nueva España, CSIC, 1964.

${ }^{2}$ BAILYN, Bernard. The challenge of modern historiography. American Historical Review, n. 87, febrero 1982, pp. 1-24.

${ }^{3}$ WEBER, David J. La frontera española en América del Norte. México: FCE, 2000, pp. 20-23.

${ }^{4}$ Imprescindible, en cuanto a las misiones, sigue siendo, pese al tiempo transcurrido, la obra de Carlos E. Castañeda, Our Catholic heritage in Texas, 1519-1936, Austin: Von Boeckmann-Jones, 7 vols. 19361958, y para una visión actual de los indios es excelente la obra de CARLSON, Paul H. The Plains Indians. Austin, Texas A\&M University Press, 1998. Excelentes bibliografías se encuentran en las obras ya citadas de David J. Weber y en la de Donald Chipman.

${ }_{5}$ Aunque apenas si se hace mención en los trabajos publicados a la figura del situado referente a las provincias del norte de Nueva España, éste constituye la pieza clave. El situado, canal de financiación militar instaurado a finales del siglo XVI por Felipe II para las Indias, consistía en el envío desde una tesorería importante de una cantidad de dinero, normalmente en metálico, hacia una guarnición que no poseía los medios suficientes para sostenerse por sí misma; es por tanto un sistema subsidial de tipo militar. A este respecto puede consultarse SERRANO, José Manuel y KUETHE, Allan J. El situado mexicano y la Cuba borbónica. En: El secreto de las finanzas del imperio español: los situados coloniales en el siglo XVIII, Instituto Mora, 2006.

${ }^{6}$ KLEIN, Herbert H. y TEPASKE, John J. The Royal treasuries of the Spanish empire in America, Durham, 1982, 3 v.; TEPASKE, John J. Ingresos y egresos de la Real Hacienda de Nueva España, Culhuacán, Instituto Nacional de Antropología, 1988; o Herbert H. Klein, Las finanzas americanas del imperio español, 1680-1809, Michoacán, Instituto José Luis Mora, 1999.

${ }^{7}$ JARA, Alvaro. "El financiamiento de la defensa en Cartagena de Indias: los excedentes de las cajas de Bogotá y de Quito, 1761-1810”, Historia, Santiago de Chile, 1994. v. 28.

${ }^{8}$ SLUITER, Engel. The Gold and silver of Spanish America, Berkeley, The Bancroft Library, 1998.

${ }^{9}$ Carlos Marichal, La bancarrota del virreinato. Nueva España y las finanzas del Imperio español, 17801810. México: FCE, 1999, p. 51.

${ }^{10}$ El profesor Allan Kuethe y yo mismo llevamos realizando un notable esfuerzo por desentrañar las fuentes estadísticas del siglo XVIII en el virreinato de Nueva España, con la idea de exponer con seguridad, y sobre bases sólidas, planteamientos globales de la política de defensa de los Borbones en el Caribe. Aunque ya hemos publicado algunas pequeñas aportaciones, los resultados más significativos irán saliendo en los próximos años en forma de varias monografías.

${ }^{11}$ Véase, a este respecto, mis dos trabajos sobre concreción de la metodología que aplico en el estudio de las cajas reales, y que han sido la base de este estudio, y de otros de similar naturaleza; SERRANO, José Manuel. Apuntes para una metodología del gasto militar en Indias. Temas Americanistas, $\mathrm{n}^{\circ}$ 15, Sevilla, 2002, pp. 32-38, y Metodología en el análisis de las cajas reales: técnicas para estudios de la administración militar en el siglo XVIII. El Mediterráneo y América, Murcia, 2006.

12 ARGÜELLES, José Canga. Diccionario de Hacienda, Madrid, Instituto de Estudios Fiscales, 1980 (edición fascímil de la original de 1833-1834), $2 \mathrm{v}$.

${ }^{13}$ MERINO, José Patricio. Las cuentas de la administración central española, 1750-1820, Madrid, Instituto de Estudios Fiscales, 1987.

${ }^{14}$ Estas son las tesis respectivas de David Chipman y Donald Worcester.

${ }^{15}$ David Chipman, op. cit. p. 141.

16 Archivo General de Indias, en adelante AGI, Guadalajara, 142, cuenta de los contadores reales de México, 4 de marzo de 1705.

${ }^{17}$ AGI, Santa Fe, 457, informe de contaduría.

${ }^{18}$ Extrapolación partiendo de los datos suministrados en SERRANO, José Manuel. Juan de Acosta y la construcción naval en La Habana, 1717-1740. En: Revista de Historia Naval, Madrid, 2006, pp. 12 y ss.

${ }^{19}$ GARCÍA, Luis Navarro. Don José de Gálvez y la Comandancia General de las Provincias Internas del Norte de Nueva España, Sevilla: CSIC, 1964, p. 61.

${ }^{20}$ Ibidem, pp. 62-63.

${ }^{21}$ WEBER, David J. La frontera española en América del norte. Fondo de Cultura Económica, 2000, pp. 219 y ss. 
${ }^{22}$ AGI, Indiferente, 108, y Chipman, op. cit., pp. 169-171.

${ }^{23}$ AGI, Guadalajara 142, informe contable.

${ }^{24}$ SERRANO, José Manuel. Situados y administración militar en Texas a mediados del siglo XVIII. Temas Americanistas, n. 18, Sevilla, 2006, pp. 19

${ }^{25}$ Datos extractados de las cuentas reales de la caja de México, AGI, Contaduría, 821, 822, 823, 824, 825. Pesos de a ocho.

${ }^{26}$ AGI, Contaduría, 817 y siguientes legajos. Informes de la contaduría de México.

${ }^{27}$ AGI, Contaduría, 824, Datos extraídos de la cuenta de real hacienda.

${ }^{28}$ AGI, Guadalajara, 144, carta al rey de 2 de marzo de 1730.

${ }^{29}$ AGI, Contaduría, 849, informe contable de 7 de noviembre de 1712.

${ }^{30}$ AGI, Contaduría, 872, informe contable de las pagas de la caja de Guadalajara

${ }^{31}$ Para un análisis detallado del derrotero de Rivera y sus vicisitudes puede consultarse fundamentalmente Vito Alessio-Robles, Diario y derrotero de lo caminado, visto y observado en la visita que hizo a los presidios de la Nueva España Septentrional el Brigadier Don Pedro de Rivera, México, Archivo Histórico Nacional, n 3, 1946.

${ }^{32}$ El Reglamento íntegro puede consultarse en AGI, Guadalajara, 144.

${ }^{33}$ AGI, México 2446, informe enviado a Ensenada el 21 de mayo de 1746.

${ }^{34}$ Este fue el caso del informe negativo elevado al virrey conde de Revillagigedo por el capitán del presidio de Conchos, José de Berroterán, de 17 de abril de 1748, en AGI, Guadalajara, 513.

35 Biblioteca Nacional de México, Parecer del marqués de Altamira sobre los autos del juicio de residencia del exgobernador de Texas, Manuel de Sandoval, practicado por su sucesor Carlos de Franquis Marqués de Altamira, 2 de mayo de 1744.

${ }^{36}$ AGI, Contaduría, 826, cuentas de la Real Hacienda.

${ }^{37}$ Ibidem.

${ }^{38}$ AGI, Contaduría, 838, cuentas de la Real Hacienda.

${ }^{39}$ Chipman, op. cit., pp. 212-214.

${ }^{40}$ Chipman, op. cit., p. 229.

${ }^{41}$ AGI, Contaduría, 839, cuentas de la Real Hacienda.

${ }^{42}$ Chipman, op. cit., p. 221.

${ }^{43}$ Jack Jackson, op. cit., p. 73.

${ }^{44}$ AGI, Contaduría, 839, cartas de la Real Hacienda.

${ }^{45}$ En términos de circulación monetaria, más de cincuenta toneladas de plata.

${ }^{46}$ WEBER, David J., op. cit., pp. 296-297.

${ }^{47}$ GARCÍA, Luis Navarro, op. cit., p. 137.

${ }^{48}$ Ibidem, p. 141.

${ }^{49}$ Jack Jackson, op. cit., p. 80.

${ }^{50}$ De hecho, Villalba era el superior inmediato de Rubí.

${ }^{51}$ Para el estudio y comprensión de las reformas militares en Cuba durante la segunda mitad del siglo XVIII, sigue siendo insustituible la obra de KUETHE, Allan J. Cuba, 1753-1815, Crown, Military and Society, Knoxville: The University of Tennessee Press, 1986.

52 AGI, México, 2146, 2147, 2148 y 2149. Cuentas de la Real Hacienda.

${ }^{53}$ En trabajos posteriores esperamos poder presentar íntegramente la masa de datos y estadísticas resultantes de esta transferencia masiva de dinero al septentrión. 